\title{
Crescimento e acumulação de nutrientes em plantas de taro sob níveis de sombreamento artificial
}

\author{
Fabio Luiz de Oliveira'; Adelson Paulo Araújo²; Jose Guilherme M Guerra ${ }^{3}$ \\ ${ }^{1}$ UFES-CCA-DPV, C. Postal 16, 29500-000 Alegre-ES; fabio.oliveira@cca.ufes.br; ${ }^{2}$ UFRRJ-Depto. Solos, 23890-000 Seropédica-RJ; \\ aparaujo@ufrrj.br; ${ }^{3}$ Embrapa Agrobiologia, C. Postal 74505, 23890-000 Seropédica-RJ; gmguerra@cnpab.embrapa.br
}

\begin{abstract}
RESUMO
Foi conduzido um experimento em vasos com solo com o objetivo de avaliar o crescimento e acumulação de nutrientes de plantas de taro (Colacasia esculenta) sob níveis de sombreamento artificial. O experimento foi constituído de quatro níveis de sombreamento $(0,25$, 50 e $75 \%$ de restrição de luz) e nove coletas mensais, no delineamento de blocos casualizados em esquema de parcelas subdivididas, com quatro repetições. Os níveis de sombreamento foram obtidos com uso de armações galvanizadas revestidas de sombrite. A restrição de luz não modificou a biomassa total das plantas, todavia sob 50 e $75 \%$ de restrição de luz a razão raiz:parte aérea foi menor. Nessas condições, as plantas tiveram maiores alturas, número de folhas e área foliar, mas menor taxa de assimilação líquida. A restrição de $75 \%$ de luz atrasou em 30 dias a formação de rizomas-filhos e reduziu a produção final de rizomas. A restrição de luz não afetou a acumulação de macronutrientes, sendo o máximo acúmulo observado aos 102 dias do plantio para N, P e K, e aos 123 dias para Ca e Mg. Condições de acentuada restrição de luz induziram investimento inicial das plantas de taro na parte aérea em detrimento de raízes, com posterior atraso na formação dos órgãos de reserva levando à redução na produção de rizomas.
\end{abstract}

Palavras-chave: Colocasia esculenta, restrição de luz, área foliar, análise de crescimento vegetal.

\begin{abstract}
Growth and nutrient accumulation of taro plants under artificial shading levels

An experiment was carried out in pots with soil to evaluate the growth and nutrient accumulation of taro plants (Colacasia esculenta) under artificial shading levels. The experiment consisted of four levels of shading $(0,25,50$ and $75 \%$ restriction of light $)$ and nine monthly samples in a split-plot randomized block design with four replications. Shading levels were obtained through cubic metal frames covered with nylon nets. The restriction of light did not change the total biomass of plants, but root:shoot ratio was lower under 50 and $75 \%$ light restriction. Under these conditions taro plants showed greater height, number of leaves and leaf area, but lower net assimilation rate. The $75 \%$ light restriction delayed cormels formation by 30 days and reduced the final cormels production. The light restriction did not affect the accumulation of macronutrients, and the maximal accumulation was observed at 102 days after planting for $\mathrm{N}, \mathrm{P}$ and $\mathrm{K}$, and 123 days for $\mathrm{Ca}$ and $\mathrm{Mg}$. Intense light restriction induced an initial investment of taro plants in the shoot rather than roots, with subsequent delay in the formation of reserve organs leading to reduced cormels production.
\end{abstract}

Keywords: Colocasia esculenta, light restriction, leaf area, plant growth analysis.

(Recebido para publicação em 29 de março de 2010; aceito em 2 de junho de 2011)

(Received on March 29, 2010; accepted on June 2, 2011)

$\mathrm{O}$ taro (Colocasia esculenta), também conhecido como inhame no centro-sul do Brasil, é a principal hortaliça da família Araceae. É uma cultura de importância econômica no estado do Rio de Janeiro, sobretudo em alguns municípios da Baixada Fluminense, como Cachoeiras de Macacu e Magé, que juntos produzem mais de $8.000 \mathrm{t} /$ ano, que representa cerca de $40 \%$ da produção da cultura no estado (CIDE, 2007).

A planta caracteriza-se pela capacidade de crescer em condições consideradas adversas a outras espécies, como excesso de água, elevada temperatura e habitat sombreado, como florestas tropicais (Imbert et al., 2004). Essa plasticidade de adaptação tem possibilitado o uso do taro em sistemas agroflorestais, inclusive em cultivos consorciados, seja entre faixas de espécies arbustivas e arbóreas (alley cropping) (Anuebunwa, 1992; Rosecrance et al., 1992; Oliveira et al., 2006), ou em linhas (Oliveira et al., 2007).

Tendo em vista a difusão de sistemas de plantio do taro em consórcio, tornam-se necessários estudos sobre o comportamento da espécie sobre diferentes condições de sombreamento, bem como a acumulação de nutrientes nessas condições. Gondim et al. (2008) observaram plasticidade anatômica da lâmina foliar do taro, cultivar Japonês, quando submetido a diferentes intensidades de sombreamento. Gondim et al. (2007), em estudo na Zona da Mata
Mineira, relataram a possibilidade da associação de culturas de maior porte com a cultura do taro, desde que haja sombreamento com intensidade de até $18 \%$, em qualquer fase do ciclo, pois não causaria diminuição significativa de produção de rizomas. No tocante ao acúmulo de nutrientes, encontram-se resultados com cultivos a pleno sol, como nos trabalhos de Puiatti et al. (1992) e Sediyama et al. (2009), sendo que esses últimos verificaram que os dois nutrientes mais exportados pelo taro 'Japonês' foram N e K, com 133 e $206 \mathrm{~kg} \mathrm{ha}^{-1}$, respectivamente.

Estudos sobre as respostas do taro ao sombreamento ainda são escassos. Tendo em vista que o comportamento da planta é influenciado por vários fatores, 
como variação genética, temperatura, luminosidade e disponibilidade de água e nutrientes, tornam-se necessários estudos de genótipos e condições climáticas diversas, para a avaliação do comportamento do taro sob sombreamento, inclusive quanto ao acúmulo de nutrientes.

Assim, no presente trabalho objetivou-se avaliar as taxas de crescimento e de acúmulo de nutrientes por plantas de taro, ecotipo 'Chinês', submetidas a níveis de sombreamento artificial, nas condições da Baixada Fluminense, estado do Rio de Janeiro.

\section{MATERIAL E MÉTODOS}

O experimento foi conduzido de setembro de 2002 a julho de 2003, na Embrapa Agrobiologia, em Seropédica-RJ, região da Baixada Fluminense, com altitude de $30 \mathrm{~m}$. Durante o período experimental, foram observados as temperatura máxima e mínima diária com termômetro digital Equitherm, umidade relativa do ar com termo-higrômetro Instrutherm, e a radiação luminosa com radiômetro LI-190SA LICOR. As medições eram efetuadas à plena luz e ocasionalmente sob algumas das armações utilizadas nos tratamentos de restrição luminosa. Durante o período do experimento, as médias da temperatura e umidade do ar foram de $23^{\circ} \mathrm{C}$ e $91 \%$, respectivamente, com pluviosidade total de $1012 \mathrm{~mm}$. A radiação luminosa a pleno sol, nas leituras realizadas às 12 horas, variou de 1100 a $1800 \mu \mathrm{mol}$ photon $/ \mathrm{m}^{2} / \mathrm{s}$.

Utilizou-se como substrato horizonte A de um Planossolo série Ecologia, com as seguintes características químicas: $\mathrm{pH}$ em água 4,6; 0,0 $\mathrm{cmol}_{\mathrm{c}} \mathrm{dm}^{-3}$ de Al; 1,5 $\mathrm{cmol}_{\mathrm{c}} \mathrm{dm}^{-3}$ de $\mathrm{Ca} ; 1,3 \mathrm{cmol}_{\mathrm{c}}$ $\mathrm{dm}^{-3}$ de $\mathrm{Mg} ; 44 \mathrm{mg} \mathrm{kg}^{-1}$ de $\mathrm{K}$ e $59 \mathrm{mg}$ $\mathrm{kg}^{-1}$ de $\mathrm{P}$ disponível. Foram acrescentados vermicomposto, cama de aviário e calcário, todos na dose de $100 \mathrm{~g} \mathrm{~kg}^{-1}$ de solo, e cinzas vegetais na dose de 50 $\mathrm{g} \mathrm{kg}^{-1}$ de solo. Todos foram misturados uniformemente ao solo, e a mistura foi acondicionada em vasos plásticos com capacidade de 10 L. Não foi feita adubação de cobertura.

Foi adotado o delineamento experimental de blocos ao acaso, em esquema de parcelas subdivididas, com quatro repetições. Nas parcelas foram dispostos os quatro níveis de sombreamento $(0$, 25,50 e $75 \%$ de restrição de luz), e nas subparcelas, as nove épocas de coletas $(30,60,90,120,150,180,210,240$ e 270 dias após plantio). Em cada vaso foi colocado um rizoma-muda, com massa média de $50 \mathrm{~g}$. Utilizou-se uma cultivar de taro originária do município de Magé-RJ, que apresenta folhas com bainha verde e rizomas com polpa branca. Esse genótipo é o mais plantado na região da Baixada Fluminense e pertence ao grupo denominado Chinês.

O sombreamento foi obtido artificialmente com armações galvanizadas de formato cúbico, com arestas de 1,5 $m$ revestidas de malha do tipo sombrite, sendo que no tratamento controle $(0 \%)$ as plantas foram mantidas sob iluminação natural. Para evitar interferência de outra fonte de sombreamento, as parcelas foram distribuídas em local isento de sombra. Os vasos foram acomodados de forma equidistante dentro das armações, em área de 2,25 $\mathrm{m}^{2}$. A cada época de coleta retirava-se o vaso mais central e rearranjava-se os vasos de forma a manter a distância equidistante entre eles. A irrigação foi diária e aferida pela capacidade de campo nos vasos.

Em cada época de coleta foi coletado um vaso por parcela. A altura da planta foi tomada do nível do solo até a inserção do pecíolo no limbo da folha de topo. As plantas foram cortadas rente ao solo e a parte aérea separada em pecíolo e limbo foliar. As folhas foram cortadas e a área foliar de cada uma delas foi obtida segundo o método de Nolasco (1984), utilizando a fórmula ajustada para o taro "Chinês" $\mathrm{A}=242,0$ $\mathrm{X}^{0,6656}$, sendo o valor de $\mathrm{X}=\mathrm{AA}$ ' $\mathrm{x} \mathrm{AB} \mathrm{x}$ AB'/1000, em que: $\mathrm{AA}^{\prime}=$ distâncias da inserção do pecíolo e a extremidade do limbo foliar; AB = distância da extremidade direita do limbo foliar à inserção do pecíolo; $\mathrm{AB}^{\prime}=$ distância da extremidade esquerda do limbo foliar à inserção do pecíolo. O material subterrâneo foi retirado do solo, lavado e separado em raízes, rizoma central e rizomas-filho. Os rizomas-filho foram contados e a matéria fresca mensurada.

Cada porção vegetal foi seca separadamente em estufa, pesada e moída. Em cada porção vegetal foram determinados o teor de $\mathrm{N}$ pelo método semi-micro Kjeldahl a partir de digestão sulfúrica, e os teores de $\mathrm{P}, \mathrm{K}, \mathrm{Ca}$ e $\mathrm{Mg}$ a partir de digestão nítrico-perclórica (Bataglia et al., 1983). O acúmulo de nutrientes foi obtido pelo produto entre o teor e a massa seca.

Os dados obtidos foram ajustados por regressão linear múltipla a diferentes modelos de crescimento, considerando o tempo como variável independente. O modelo exponencial polinomial de $3^{\circ}$ grau foi escolhido por apresentar maior R2 e significância de todos os coeficientes da regressão; os coeficientes obtidos são apresentados na Tabela 1 . As taxas de crescimento e de acumulação de nutrientes foram estimadas pelo método funcional de análise de crescimento (Hunt, 1982). Por derivação dos modelos ajustados aos dados de massa seca total (W) e área foliar (A), foram estimados valores instantâneos da taxa de crescimento absoluto $(\mathrm{TCA}=\mathrm{dW} /$ dT) e da taxa de assimilação líquida $(\mathrm{TAL}=(1 / \mathrm{A}) \times(\mathrm{dW} / \mathrm{dT}))$, no tempo $(\mathrm{T})$. A área foliar específica foi obtida pela razão entre a área foliar e a massa seca de folha.

Para os dados de número de rizomas e massa fresca de rizoma, foi efetuada uma análise de variância para cada época de coleta isoladamente, avaliando o efeito dos níveis de sombreamento, sendo as médias comparadas pelo teste de Tukey a 5\% (Araújo, 2003).

\section{RESULTADOS E DISCUSSÃO}

A temperatura e umidade relativa do ar foram bastante similares quando mensuradas dentro e fora das armações, em função da localização do experimento propícia aos ventos, o que possivelmente promoveu trocas constantes entre os dois ambientes. Desta forma, as diferenças observadas entre os tratamentos de restrição de luz não podem ser atribuídas a diferenças nos parâmetros climáticos.

Sob $75 \%$ de restrição de luz, observou-se maior altura das plantas de taro em todas as datas de avaliação (Figura 1), demonstrando que a baixa luminosidade estimula o alongamento do pecíolo buscando maior captação de raios sola- 


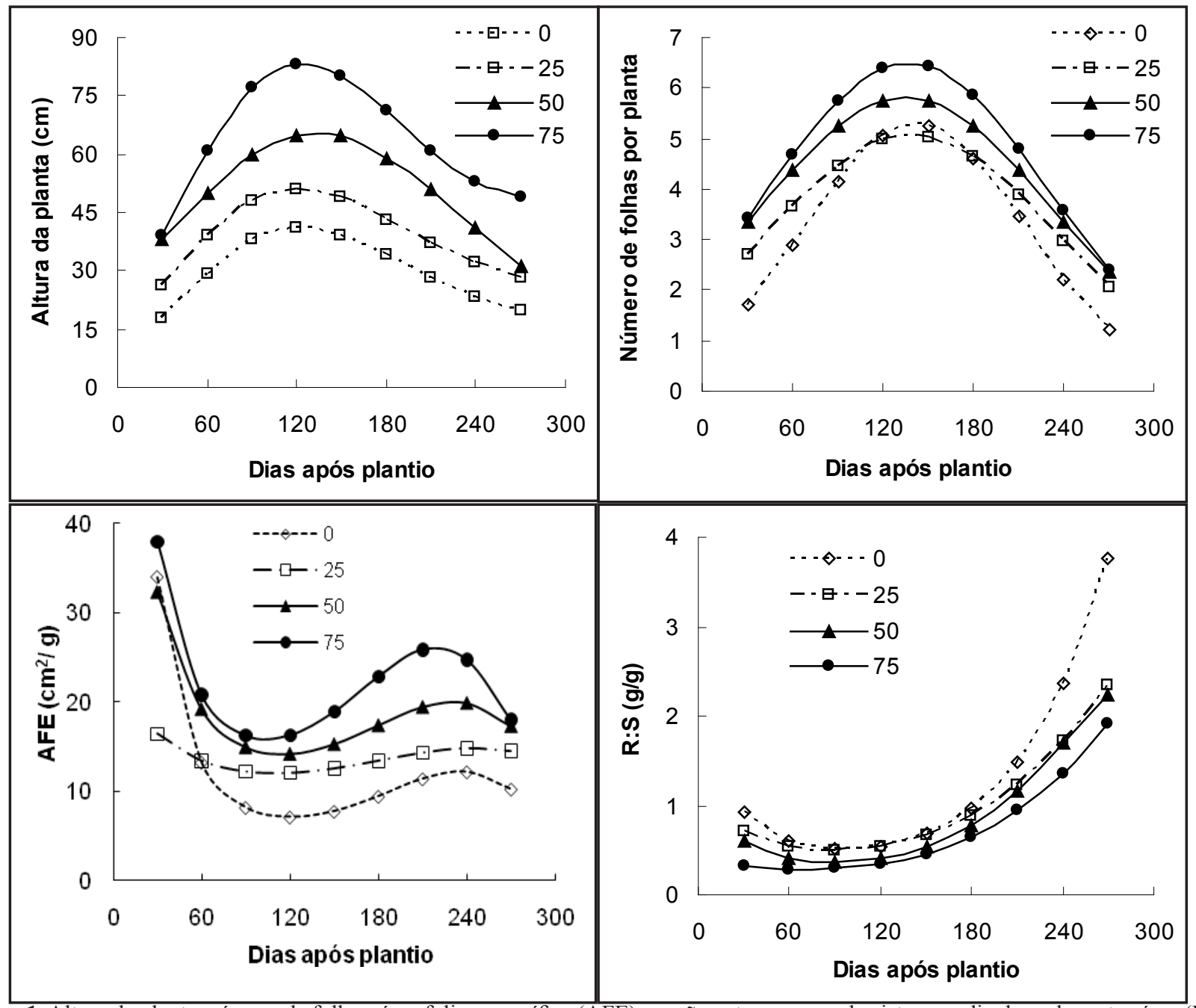

Figura 1. Altura da planta, número de folhas, área foliar específica (AFE) e razão entre a massa do sistema radicular e da parte aérea (R:S), durante o ciclo de cultivo de plantas de taro sob diferentes níveis de sombreamento artificial (plant height, number of leaves, specific leaf area and root:shoot mass ratio during the growth cycle of taro plants under different artificial shading levels). Seropédica, UFRRJ e Embrapa Agrobiologia, 2004.

res. O número de folhas aumentou até os 120-150 dias do plantio e reduziu-se após, indicando um processo de abscisão foliar ao final do ciclo (Figura 1). Sob $75 \%$ de restrição de luz, observou-se maior número de folhas até os 180 dias de ciclo, em comparação às plantas sob plena luz (Figura 1). Entre os $210 \mathrm{e}$ 240 dias do plantio, o número de folhas foi similar nos diferentes tratamentos; todavia, ao final do ciclo, as plantas sem restrição luminosa apresentaram menor número de folhas, indicando ter havido senescência foliar mais intensa sob plena luz.

Nos tratamentos com restrição de luz foram observados maiores valores de área foliar específica, sobretudo dos 180 aos 240 dias após plantio (Figura 1), denotando a produção de folhas mais finas de taro sob baixa luminosidade. Esses resultados assemelham-se aos de Gondim et al. (2008), que observaram que o sombreamento promovia redução da espessura da folha em plantas da cultivar Japonês. Esse comportamento constitui uma resposta fisiológica típica das plantas sob restrição de luz, com estímulo à expansão do limbo foliar e alongamento dos caules e pecíolos (Wilson et al., 1999). Em plantas de mandioca cultivadas em faixas intercalares de leucena e guandu, Leihner et al. (1996) também registraram comportamento similar, quanto à expansão foliar e alongamento dos caules e pecíolos.

Plantas sob restrição de luz apresentaram menores valores da razão raiz:parte aérea aos 30 dias do ciclo (Figura 1), o que demonstra que sob restri- ção luminosa ocorreu um investimento preferencial na formação de parte aérea em detrimento das raízes, priorizando-se a captação de luz. Dos 60 aos 150 dias, esta partição de biomassa se estabilizou, e a partir de 180 dias, ocorreu novamente maior investimento proporcional na parte aérea nas plantas sob forte restrição de luz, acompanhando a maior área foliar (Figura 1). Gondim et al. (2007) também observaram em plantas de taro, cultivar Japonês, crescendo sob forte restrição de luz, um investimento preferencial de fotoassimilados na formação da parte área em detrimento dos rizomas-filho. Analogamente, Faukai et al. (1984) observaram o favorecimento da produção de folhas em relação às raízes pela mandioca, a partir de $22 \%$ de restrição de luz. 


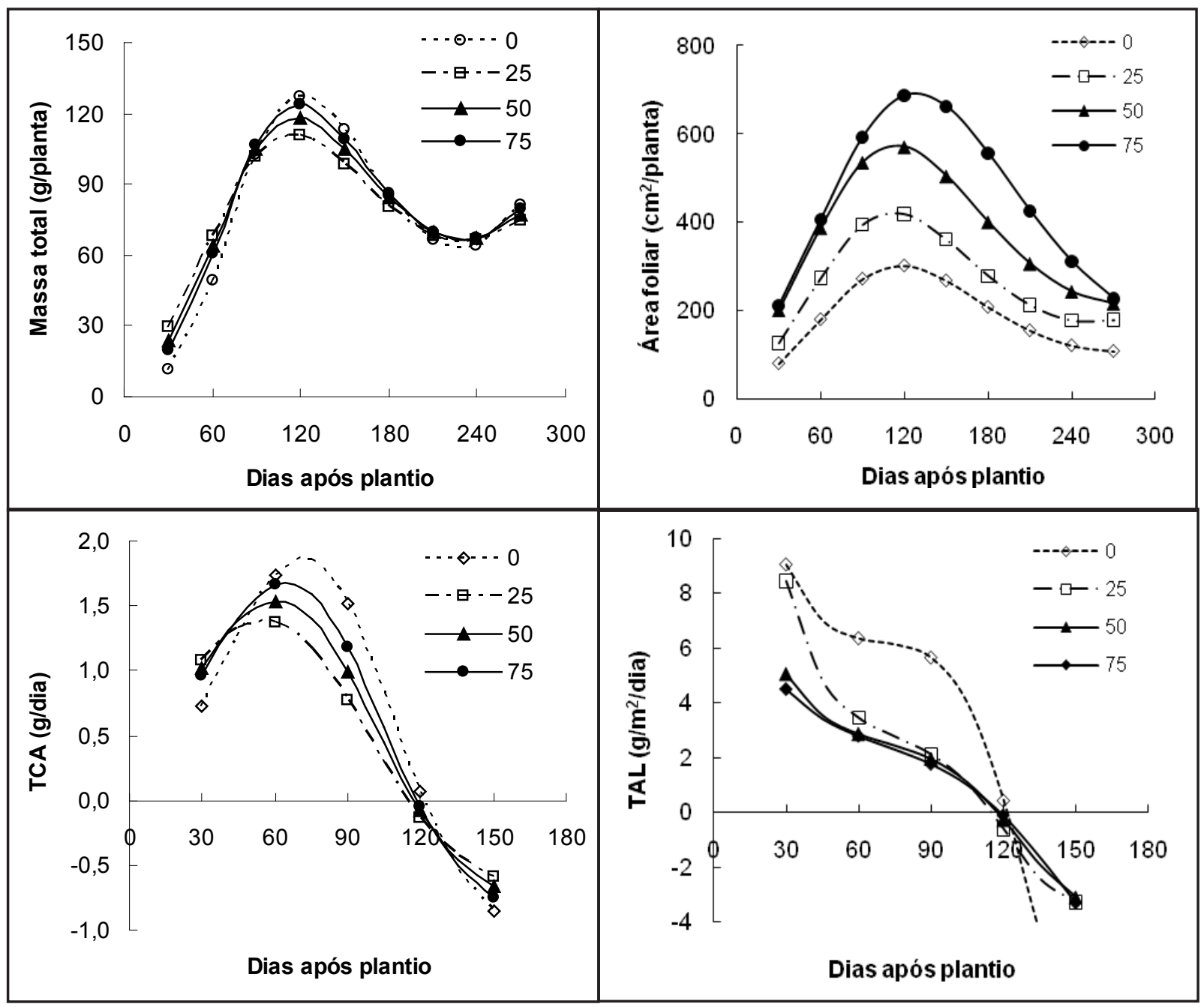

Figura 2. Massa seca total (parte aérea e raiz), área foliar, taxa de crescimento absoluto (TCA) e taxa de assimilação líquida (TAL), durante o ciclo de cultivo de plantas de taro crescidas sob diferentes níveis de sombreamento artificial (total dry mass, leaf area, absolute growth rate and net assimilation rate during the growth cycle of taro plants grown under different artificial shading levels). Seropédica, UFRRJ e Embrapa Agrobiologia, 2004.

Os níveis de restrição de luz não influenciaram o acúmulo de matéria seca total das plantas de taro, sendo observados valores máximos aos 115 dias de ciclo com posterior redução da biomassa (Figura 2). Essa redução de biomassa após os 115 dias está relacionada com o início do processo de senescência foliar e de realocação de nutrientes e assimilados dentro da planta, que estariam sendo enviados para os órgãos de reserva, sobretudo rizomas-filho (Figura 3). Gondim et al. (2007) também observaram esse comportamento na cultivar Japonês, e Puiatti et al. (1992) observaram comportamento semelhante, em condições de campo, porém com valores superiores de acúmulo de matéria seca, para a cultivar Chinês, ambos nas condições de Viçosa-MG.
Em todos os tratamentos de restrição luminosa os valores máximos de área foliar ocorreram entre os 120 e 150 dias do ciclo (Figura 2), assim como observado por Zarate (1988). A partir deste período, ocorreu uma redução contínua da área foliar em virtude da senescência e abscisão de folhas. Ao longo do ciclo, os maiores valores de área foliar ocorreram sob $75 \%$ de restrição de luz (Figura 2), demonstrando que a limitação de luz estimula a expansão da lâmina foliar visando aumentar a área de captação de raios solares. Estes resultados corroboram com os de Gondim et al. (2008), que observaram plasticidade anatômica da lâmina foliar em plantas de taro, cultivar Japonês, quando submetidas a diferentes intensidades de sombreamento, o que provavelmente interfere em sua capa- cidade fotossintética e redistribuição de fotoassimilados nos órgãos vegetativos.

A taxa de crescimento absoluto foi crescente até os 60 dias após plantio, reduzindo-se a partir deste período, demonstrando redução na velocidade de produção de biomassa com a ontogenia vegetal (Figura 2). A partir de 120 dias, a taxa de crescimento absoluto assume valores negativos, em consequência da redução da massa total da planta (Figura 1). Desta forma, os valores das taxas de crescimento absoluto e de assimilação líquida são representados até 150 dias após plantio, pois em estádios posteriores foram estimados valores negativos erráticos destas taxas, de pouco significado biológico (Hunt, 1982). No início do ciclo observaram-se valores da taxa de crescimento absoluto ligeiramente 


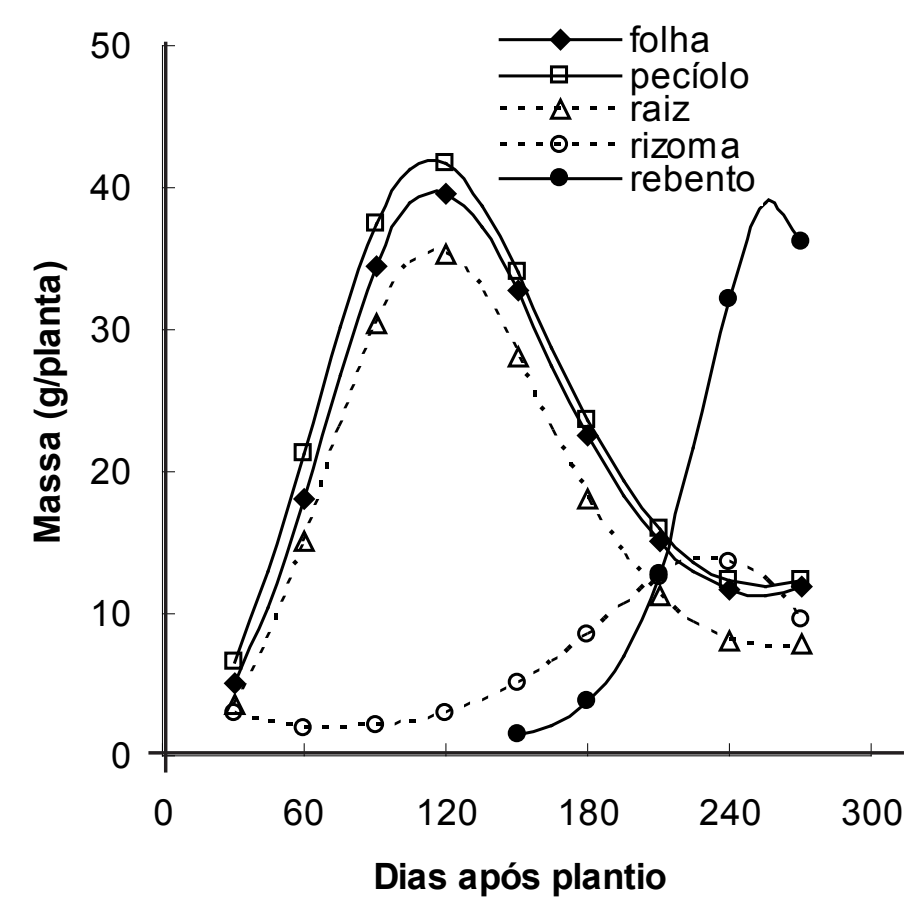

Figura 3. Massa seca de cada órgão vegetal (limbo foliar, pecíolo, raiz, rizoma e rebentos), de plantas de taro durante o ciclo de cultivo (dry mass of each part of taro plants during the growth cycle). Seropédica, UFRRJ e Embrapa Agrobiologia, 2004.

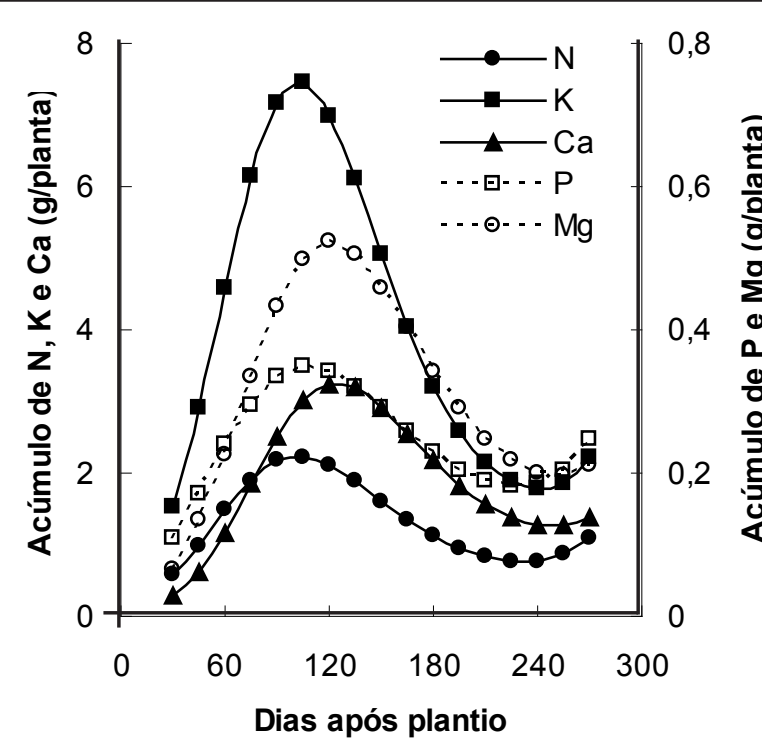

Figura 4. Acumulação de N, P, K, Ca e Mg em plantas de taro durante o ciclo de cultivo (accumulation of N, P, K, Ca and Mg by taro plants during the growth cycle). Seropédica, UFRRJ e Embrapa Agrobiologia, 2004.

superiores nas plantas crescendo sob restrição de luz, mas após os 60 dias de ciclo, as maiores taxas de crescimento ocorreram nas plantas crescendo sob plena luz (Figura 2).
A taxa de assimilação líquida, que indica a velocidade de acumulação de biomassa por unidade de área foliar, decresceu até assumir valores negativos a partir dos 120 dias de ciclo (Figura
2), indicando que dessa data em diante, a atividade fotossintética passou a ser menor que a respiratória, além da ocorrência de senescência foliar. A taxa de assimilação líquida foi menor nas plantas crescendo sob sombreamento, indicando menor atividade fotossintética por unidade de área foliar. Esta menor taxa de assimilação líquida nas plantas sob restrição luminosa pode estar associada à maior área foliar específica, ou seja, a baixa luminosidade induziu a produção de folhas mais finas, mas com maior área de interceptação de luz (Milla et al., 2008).

Os máximos acúmulos de massa seca nos órgãos de parte aérea (folha e pecíolo) e nas raízes das plantas de taro ocorreram em torno de 120 dias após plantio; por outro lado, no rizoma central e nos rizomas filhos ocorreu, respectivamente, em torno dos 240 e 270 dias do ciclo (Figura 3). Esse comportamento é similar ao observado em taro por Puiatti et al. (1992) e por Gondim et al. (2007) na cultivar Japonês. Isto ilustra que o processo de alocação de fotossintatos para os diferentes órgãos vegetais dessa espécie ocorre em momentos característicos, com um investimento preferencial inicial na parte aérea e raízes para captação de luz, água e nutrientes. Ao final do ciclo há uma intensa translocação de assimilados para órgãos de reserva, inicialmente ao rizoma central e posteriormente aos rizomas-filho, que são caules subterrâneos usados para propagação vegetativa dessa espécie.

Sob os níveis de 25 e $50 \%$ de restrição de luz, houve maior número final de rizomas-filho por planta (média de 8 rebentos), em comparação às plantas crescendo sob luz natural e $75 \%$ de restrição de luz (média de 5 rebentos) (Tabela 2). Além disso, no maior nível de restrição de luz (75\%) ocorreu atraso em 30 dias no início da formação de rizomas-filho. A massa fresca final de rizomas-filho foi menor sob o nível de $75 \%$ de restrição de luz, quando comparado aos níveis de 0 e $25 \%$ de restrição (Tabela 2). Essa diferença na produção final de rizomas-filho pode ser reflexo da partição diferencial de biomassa, ou seja, sob forte sombreamento as plantas de taro utilizaram maior quantidade de fotoassimilados para manutenção de 
Tabela 1. Coeficientes do modelo exponencial polinomial de $3^{\circ}$ grau, $Y=\exp \left(a+b t+c t^{2}+d t^{3}\right)$, ajustado aos dados de plantas de taro crescidas sob níveis de sombreamento artificial, durante o ciclo de cultivo (coefficients of the third degree exponential polynomial model adjusted to data of taro plants grown under artificial shading levels during growth cycle). Seropédica, UFRRJ e Embrapa Agrobiologia, 2004.

\begin{tabular}{lcccccc}
\hline Característica & $\begin{array}{c}\text { Restrição } \\
\text { de luz }\end{array}$ & $\mathbf{a}$ & $\mathbf{b}$ & $\mathbf{c}$ & $\mathbf{d}$ & $\mathbf{R}^{2}$ \\
\hline Massa seca total & 0 & 0,15 & 0,09 & $-5,91 \mathrm{e}-4$ & $1,12 \mathrm{e}-6$ & 0,87 \\
& 25 & 1,99 & 0,06 & $-3,72 \mathrm{e}-4$ & $7,21 \mathrm{e}-7$ & 0,89 \\
& 50 & 1,54 & 0,07 & $-4,26 \mathrm{e}-4$ & $8,18 \mathrm{e}-7$ & 0,87 \\
& 75 & 1,14 & 0,07 & $-4,78 \mathrm{e}-4$ & $9,14 \mathrm{e}-7$ & 0,89 \\
\hline Área foliar & 0 & 0,77 & 0,05 & $-3,23 \mathrm{e}-4$ & $5,54 \mathrm{e}-7$ & 0,74 \\
& 25 & 1,27 & 0,05 & $-3,35 \mathrm{e}-4$ & $6,09 \mathrm{e}-7$ & 0,65 \\
& 50 & 1,94 & 0,04 & $-2,68 \mathrm{e}-4$ & $4,59 \mathrm{e}-7$ & 0,72 \\
& 75 & 2,08 & 0,04 & $-2,04 \mathrm{e}-4$ & $2,83 \mathrm{e}-7$ & 0,73 \\
\hline
\end{tabular}

folhas ao final do ciclo, retardando a senescência foliar, em detrimento da translocação de assimilados para os órgãos de reserva. Gondim et al. (2007) também observaram que a restrição de luz, sobretudo no período intermediário de crescimento, resultou em menor quantidade de fotoassimilados para serem distribuídos aos rizomas-filho.

Considerando uma densidade hipotética de 30.000 plantas/ha, usualmente praticada pelos produtores no estado do Rio de Janeiro, os resultados indicam um rendimento médio de $22 \mathrm{t} \mathrm{ha}^{-1} \mathrm{de}$ rizomas, acima da produtividade média de 15 t ha $^{-1}$ do estado do Rio de Janeiro (CIDE, 2007). Deve-se ressaltar que sob plena luz foram produzidos rizomas-filhos de maior tamanho, como indicado pela razão entre a massa fresca e o número de rizomas (Tabela 1), e estes maiores rizomas podem obter maior
165 dias.

$\mathrm{O} \mathrm{K}$ foi o nutriente acumulado em maiores quantidades pelas plantas de taro, seguido pelo $\mathrm{Ca}, \mathrm{N}, \mathrm{Mg}$ e P (Figura 4), corroborando com resultados de Puiatti et al. (1992) em observações a campo. Considerando uma densidade de 30.000 plantas de taro/ha, esses resultados significariam um acúmulo de $225 \mathrm{~kg}$ de $\mathrm{K}, 105 \mathrm{~kg}$ de $\mathrm{Ca}, 75 \mathrm{~kg}$ de N, por hectare plantado com a cultivar Chinês. Isto retrata uma grande capacidade de extração desses nutrientes por essa cultivar, demonstrando a necessidade da realização da prática da adubação em momentos que antecedam o pico de acumulação, aos 102 dias de ciclo para $\mathrm{N}$ e K, e aos 123 dias para Ca.

Considerando os teores de nutrientes nos rizomas-filho aos 270 dias após o plantio $\left(14,4 ; 4,3 ; 29,0 ; 2,6\right.$ e $1,6 \mathrm{~g} \mathrm{~kg}^{-1}$, respectivamente, para $\mathrm{N}, \mathrm{P}, \mathrm{K}, \mathrm{Ca}$ e $\mathrm{Mg}$ ), e a estimativa de rendimento médio de $22 \mathrm{t} \mathrm{ha}^{-1}$, verifica-se um potencial de exportação pelos rizomas-filho de $79 \mathrm{~kg}$ $\mathrm{ha}^{-1}$ de N, $24 \mathrm{~kg} \mathrm{ha}^{-1}$ de P, $160 \mathrm{~kg} \mathrm{ha}^{-1} \mathrm{de}$ $\mathrm{K}, 14 \mathrm{~kg} \mathrm{ha}^{-1} \mathrm{de} \mathrm{Ca}$, e $9 \mathrm{~kg} \mathrm{ha}^{-1} \mathrm{de} \mathrm{Mg}$. Sendo assim, a porção comercializável da cultura do taro pode extrair quantidades relevantes de $\mathrm{K}$ e N (Sediyama et al., 2009).

Em conclusão, os resultados obtidos indicam que condições de acentuada restrição luminosa (50 e 75\% de restrição de luz) induzem um investimento inicial das plantas de taro Chinês no crescimento da parte aérea e na expansão da área foliar em detrimento da produção de raízes. Em conseqüência, a intensa restrição luminosa acarreta, posteriormente,

Tabela 2. Número e massa fresca de rizomas-filho de plantas de taro crescidas sob níveis de sombreamento artificial, durante o ciclo de cultivo (number and fresh mass of tillers of taro grown under artificial shading levels during growth cycle). Seropédica, UFRRJ e Embrapa Agrobiologia, 2004.

\begin{tabular}{|c|c|c|c|c|c|c|c|c|}
\hline \multirow{2}{*}{$\begin{array}{l}\text { Dias após } \\
\text { plantio }\end{array}$} & \multicolumn{8}{|c|}{ Níveis de restrição de luz (\%) } \\
\hline & $\mathbf{0}$ & 25 & 50 & 75 & $\mathbf{0}$ & 25 & 50 & 75 \\
\hline & \multicolumn{4}{|c|}{ Rizomas-filho (noo/planta) } & \multicolumn{4}{|c|}{ Massa fresca de rizomas-filho (g/planta) } \\
\hline 120 & $3,2 \mathrm{a}^{*}$ & $3,0 \mathrm{a}$ & $0,7 \mathrm{~b}$ & $0,0 \mathrm{c}$ & $13 \mathrm{a}^{*}$ & $12 \mathrm{a}$ & $4 \mathrm{~b}$ & $0 \mathrm{c}$ \\
\hline 150 & $7,0 \mathrm{a}$ & $6,5 \mathrm{a}$ & $6,2 \mathrm{a}$ & $2,5 \mathrm{~b}$ & $31 \mathrm{a}$ & $33 \mathrm{a}$ & $37 \mathrm{a}$ & $20 \mathrm{~b}$ \\
\hline 180 & $8,5 \mathrm{a}$ & $6,5 \mathrm{ab}$ & $8,5 \mathrm{a}$ & $5,0 \mathrm{~b}$ & $78 \mathrm{a}$ & $81 \mathrm{a}$ & $74 \mathrm{ab}$ & $69 \mathrm{~b}$ \\
\hline 210 & $9,0 \mathrm{a}$ & $7,2 \mathrm{a}$ & $7,7 \mathrm{a}$ & $4,5 \mathrm{~b}$ & $250 \mathrm{a}$ & $250 \mathrm{a}$ & $260 \mathrm{a}$ & $245 \mathrm{a}$ \\
\hline 240 & $9,0 \mathrm{a}$ & $8,2 \mathrm{a}$ & $8,2 \mathrm{a}$ & $6,0 \mathrm{~b}$ & $655 \mathrm{a}$ & $655 \mathrm{a}$ & $648 \mathrm{a}$ & $650 \mathrm{a}$ \\
\hline 270 & $5,2 \mathrm{~b}$ & $8,0 \mathrm{a}$ & $8,0 \mathrm{a}$ & $5,0 \mathrm{~b}$ & $755 \mathrm{a}$ & $736 \mathrm{a}$ & $729 \mathrm{ab}$ & $705 \mathrm{~b}$ \\
\hline
\end{tabular}

${ }^{*}$ Médias seguidas de mesma letra dentro da mesma linha não diferem pelo teste de Tukey, $\mathrm{p}<0,05$ (means followed by the same letter within the same line do not differ by Tukey test, $\mathrm{p}<0.05$ ). 
atraso na formação das estruturas de reserva e uma redução na produtividade de rizomas-filho. Por outro lado, condições de moderada restrição luminosa $(25 \%$ de restrição de luz) não modificaram os padrões de crescimento e de acumulação de nutrientes, em comparação às plantas crescidas sob plena luz, indicando que a cultura do taro pode ser associada a cultivos consorciados que promovam um moderado sombreamento.

\section{REFERÊNCIAS}

ANUEBUNWA FO. 1992. A bio-economic evaluation of intercropping arrangements in a yam-cassava based cropping system in the rain forest belt of Nigeria. Biological Agriculture and Horticulture 8: 251-260.

ARAÚJO AP. 2003. Analysis of variance of primary data on plant growth analysis. Pesquisa Agropecuária Brasileira 38: 1-10.

BATAGLIA OG; FURLANI AMC; TEIXEIRA JPF; GALLO JR. 1983. Métodos de análise quimica de plantas. Campinas: IAC. $35 \mathrm{p}$. (IAC, Boletim 78).

CIDE - CENTRO DE INFORMAÇÕES E DADOS DO RIO DE JANEIRO. 2007. Anuário estatístico do Estado do Rio de Janeiro. Rio de Janeiro: CIDE. 279p.

FAUKAI S; ALCOY AB; LLAMELO AB; PATTERSON RD. 1984. Effects of solar radiation on growth and yield of cassava
(Manihot esculenta): I-Canopy development and dry matter growth. Field Crops Research 9: 347-360.

GONDIMARO; PUIATTI M; VENTRELLAMC; CECON PR. 2008. Plasticidade anatômica da folha de taro cultivado sob diferentes condições de sombreamento. Bragantia 67: 1037-1045.

GONDIM ARO; PUIATTI M; CECON PR; FINGER FL. 2007. Crescimento, partição de fotoassimilados e produção de rizomas em taro cultivado sob sombreamento artificial. Horticultura Brasileira 25: 418-422.

HUNT R. 1982. Plant growth curves: The functional approach to plant growth analysis. London: Edward Arnold. 248p.

IMBERT D; SAUR E; BONHEME I; ROSEAU V. 2004. Traditional taro (Colocasia esculenta) cultivation in the swamp forest of Guadeloupe (FWI): Impact on forest structure and plant biodiversity. Revue d'Ecologie 59: 181-189.

LEIHNER DE; ERNST-SCHAEBEN R; AKONDÉ TP; STEINMULLER N. 1996. Alley cropping on an Ultisol in subhumid Benin. Part 2: Changes in crop physiology and tree crop competition. Agroforestry Systems 34: 13-25.

MILLA R; REICH PB; NIINEMETS Ü; CASTRO-DÍEZ P. 2008. Environmental and developmental controls on specific leaf area are little modified by leaf allometry. Functional Ecology 22: 565-576.

NOLASCO, F. 1984. Estudos para o cultivo inundado de inhame (Colocasia esculenta), em monocultivo e em consórcio com Azolla. Viçosa: UFV. 80p. (Dissertação mestrado).
OLIVEIRA FL; GUERRA JGM; JUNQUEIRA RM; SILVAEE; OLIVEIRAFF; ESPINDOLA, JAA; ALMEIDA DL; RIBEIRO RLD; URQUIAGA S. 2006. Crescimento e produtividade do inhame cultivado entre faixas de guandu em sistema orgânico. Horticultura Brasileira 24: 53-58.

OLIVEIRA FL; GUERRA JGM; RIBEIRO RLD; URQUIAGA S; ESPINDOLA JAA. 2007. The use of sunn hemp as green manure intercropped with taro. Horticultura Brasileira 25: 556-560.

PUIATTI M; GREEMAN S; KATSUMOTO R; FAVERO C. 1992. Crescimento e absorção de macronutrientes pelo inhame 'chinês' e 'japonês'. Horticultura Brasileira 10: 89-92.

ROSECRANCE RC; ROGERS S; TOFINGA M. 1992. Effects of alley cropped Calliandra calothyrsus and Gliricidia sepium hedges on weed growth, soil properties and taro yields in western Samoa. Agroforestry Systems 19: 57-66.

SEDIYAMA MAN; SANTOS MR; SALGADO LT; PUIATTI M; VIDIGAL SM. 2009. Produtividade e exportação de nutrientes por rizomas de taro cultivado com resíduos orgânicos. Revista Brasileira de Ciências Agrárias 4: 421-425.

WILSON PJ; THOMPSON K; HODGSON JG. 1999. Specific leaf area and leaf dry matter content as alternative predictors of plants strategies. New Phytologist 143: 155-162.

ZARATE NAH. 1988. Curvas de crescimento de inhame (Colocasia esculenta) considerando cinco populações, em solo seco e alagado. Viçosa: UFV. 94p. (Tese doutorado). 